\section{Slavinska 0., Tsynka A.}

\title{
DETERMINATION OF THE INFLUENCE AREA OF A BRIDGE CROSSING IN A RIVER STREAM
}

The object of research is the formation of the influence zone of the bridge crossing in the river flow. The method for determining the length of the zone of influence of the bridge crossing provides for the calculation of such parameters as the specific discharge of floodplains, the length of the zones of compression and spreading, and the full backwater in front of the bridge section. The proposed approach is based on changing the properties of the central stream of the river flow in the zone of artificial influence of the bridge structure. Determination of the flow depth and the inclined free surface is carried out according to the corresponding finite-difference analogs of differential equations describing the change in these quantities. All calculations are made, respectively, for each branch of a flood or flood, for a certain day. Calculations start with a full spreading alignment, where all hydraulic characteristics of the flow have natural values.

The paper presents the calculation of the zone of influence of the bridge crossing on the river Seversky Donets on the T-05-14 highway within the Donetsk region (Ukraine). It has been established that the development of general channel deformations in the channel and on the floodplains occurs in a section from $1195 \mathrm{~m}$ to $2144 \mathrm{~m}$ long. The distribution of the river flow depth is obtained, which increases from $0.58 \mathrm{~m}$ to $2.17 \mathrm{~m}$ in the alignment of the bridge crossing after the flood. With an increase in the flow rate of the river flow, the parameters of the compression zone also increase from $246 \mathrm{~m}$ to $1382 \mathrm{~m}$, and the spreading zones decrease from $949 \mathrm{~m}$ to $762 \mathrm{~m}$. The change in the parameter of the central jet occurs in accordance with the distribution of the compression and spreading zones during the course of the flood. The obtained results are the initial conditions for conducting research on predicting eroded processes in a river flow, taking into account artificial compression in the zone of influence of the bridge crossing.

Keywords: bridge crossing, floodplain, influence zone of the bridge, zone of river compression, spreading zone of the river.

Received date: 14.04 .2020

Accepted date: 19.05.2020

Published date: 31.08 .2020
Copyright (C) 2020, Slavinska O., Tsynka A. This is an open access article under the CC BY license (http://creativecommons.org/licenses/by/4.0)

\section{Introduction}

Predictions of the possible inflow of water to the bridge and the development of inevitable channel deformations are the basis for the correct assignment of the required dimensions of the bridge crossing structures. The greater the compression of the river flow, the greater the channel deformations become and, as a consequence, the depth of the supports sinking increases. With a decrease in the opening of the bridge passage, the total support in front of the bridge increases, which induces an increase in the embankments of approaches and spans. With a large compression of the river, in conditions of intense work of the crossing, certain types of regulatory structures are also provided. Accordingly, the actual question is to determine the dominant characteristic of the bridge crossing - the width of the opening, which determines the length of the bridge and its other parameters.

\section{The object of research and its technological audit}

The object of research is the formation of the influence zone of the bridge crossing in the river flow.

The general erosion of the river flow is formed in the influence zone of the bridge crossing, which in length consists of two zones - compression and spreading. Com- pression zone is the zone of the upper reach of the bridge, where there is an increase in the channel flow along the river and, accordingly, the convergence of the streamlines of the river flow, it is limited by the section of the beginning of compression and the section of the bridge. The spreading zone is the zone of the downstream of the bridge crossing, where there is a decrease in channel flow rates and, accordingly, an increase in flow on the floodplains along the river, it is limited by the section of the bridge crossing and the section of full spreading, where the natural regime of the river is restored.

\section{The aim and objectives of research}

The aim of research is to determine the parameters of the influence zone of the bridge crossing, where the formation of general erosion (development of general deformations) in the river flow occurs. To do this, it is necessary to complete the following tasks:

1. To develop a method for determining the length of compression and spreading zones, taking into account the parameters of the central jet and a mathematical model of the level change and the inclined free surface of the river flow.

2. To calculate the parameters of the influence zone of the bridge crossing on a flat river using the proposed method. 


\section{Research of existing solution of the problem}

In [1], based on the results of field and laboratory studies, a three-dimensional model of the river with zones of bends, confluence and separation of the flow is presented. The model is proposed to predict changes in the configuration of the channel and floodplain, as well as the transport of river sediments. The division of the river, in particular the floodplain flow into zones depending on the mode of sediment transport, their deposition in floodplain areas, is presented in [2]. Prediction of sediment transport in order to eliminate the consequences of the passage of floods and floods in the zones of river flow bends are given in [3]. The studies in the mentioned works are presented for natural zones, without taking into account the presence of artificial structures and the corresponding effect of artificial compression on the velocity structure of the river flow.

In order to predict the eroded processes in the zone of the bridge crossing, the velocity structure of the river flow at the bend is modeled in [4]. The studies are based on one-dimensional and two-dimensional models of the channel by the finite element method, but the determination of the magnitude of deformations in the floodplains has not been proposed.

The study of flood runoff in the area of the bridge crossing is considered in work [5]. The authors presents the results of experimental studies on the throughput of the river flow directly in the alignment of the bridge, the development of local erosion at bridge supports and the parameters of the velocity structure in floodplain areas. The work [6] shows the change in the flow depth, considers the zones of conditional separation of the channel and floodplain flows, the influence of their configurations on the eroded processes. The influence of the construction of the bridge on the hydrology of floodplains within large cities is analyzed in [7]. Within the framework of the presented study, a conceptual assessment of morphological changes in the river and its floodplain was carried out. The influence of the configuration of river flows, forms of cross-sections of channels and floodplains on the velocity structure, changes in depths are investigated on the basis of numerical experiments in [8]. The determination of the boundaries of the influence of the bridge crossing on the basis of field observations or the results of a numerical experiment is not analyzed in [5-8].

The study of the development of general erosion in the downstream of hydraulic structures on the basis of modeling sediment transport and deformation processes in the channel in an uneven flow is presented in [9]. In [10], the dependence of the relative depth of erosion on the degree of compression of the river flow is established. But in the above boundary conditions, in [9, 10], it is precisely the parameters of the zones of influence of the hydraulic engineering construction that are not indicated.

Thus, the results of the analysis allow to conclude that the determination of the influence zone of artificial compression of hydraulic structures, bridge crossings in particular, is an urgent task in predicting deformation processes in river flows.

\section{Methods of research}

The method for determining the length of the influence zone of a bridge crossing in a river flow is based on the approach proposed in [11, 12]. Based on the analysis of hydraulic phenomena at the bridge crossing according to the channel flow rate transformation, the dependences of the change in the parameters of the central stream of the river flow are obtained. At the beginning of the calculation, the basic initial data are specified that characterize the general parameters of the computational domain (Table 1).

Table 1

Output data of calculating the influence zone of a bridge crossing

\begin{tabular}{|c|l|c|c|c|}
\hline No. & \multicolumn{1}{|c|}{ Parameter name } & Mark & Unit & $\begin{array}{c}\text { Parameter } \\
\text { value }\end{array}$ \\
\hline 1 & Longitudinal slope of the bottom & $J$ & - & 0.00018 \\
\hline 2 & Average elevation of the channel bottom & $Z^{r}$ & - & 143.7 \\
\hline 3 & Average elevation of the floodplain bottom & $Z_{f-p}$ & - & 146.64 \\
\hline 4 & Acceleration of gravity & $g$ & $\mathrm{~m} / \mathrm{s}^{2}$ & 9.81 \\
\hline 5 & Hiver flood width & $B_{r i v}$ & $\mathrm{~m}$ & 466.3 \\
\hline 6 & Average channel width & $B_{r}$ & $\mathrm{~m}$ & 58.11 \\
\hline 7 & Average width of the greater floodplain & $b_{f-p b}$ & $\mathrm{~m}$ & 212.26 \\
\hline 8 & Average width of the lesser floodplain & $b_{f-p s}$ & $\mathrm{~m}$ & 149.08 \\
\hline 9 & Aoughness coefficient on floodplains & $N$ & - & 0.067 \\
\hline 10 & Bridge opening width & $B_{b r}$ & $\mathrm{~m}$ & 267 \\
\hline
\end{tabular}

The calculation provides for a sequence with the determination of the following values. Determine the natural specific discharge of floodplains:

$$
q_{f-p}=\frac{Q_{r i v}-Q_{r}}{B_{r i v}-B_{r}},
$$

where $Q_{\text {riv }}$ - total discharge of the river, $\mathrm{m}^{3} / \mathrm{s} ; Q_{r}-$ river channel discharge, $\mathrm{m}^{3} / \mathrm{s} ; B_{\text {riv }}$ - width of the river flood, $\mathrm{m}$; $B_{r}$ - average channel width, $\mathrm{m}$.

The compression ratio of the river flow is calculated:

$$
\beta_{b r}=\frac{Q_{r i v}}{Q_{r}+q_{f-p}\left(B_{b r}-B_{r}\right)},
$$

Determine the length of the influence of the bridge crossing:

$$
l_{z_{-} b r}=\frac{h_{r}}{J} \frac{\left(\frac{\beta_{b r}^{2}}{2 \beta_{b r}-1}\right)^{0.3}-1}{\beta_{b r}-1},
$$

where $B_{b r}$ - the width of the bridge opening, m; $J$ - longitudinal slope of the bottom; $h_{r}$ - channel depth, $\mathrm{m}$.

Calculate the cross-sectional area of the river flow:

$$
\omega_{r i v}=B_{r} h_{r}+b_{f-p} h_{f-p},
$$

where $b_{f-p}$ - the average width of the floodplain (larger and smaller), $\mathrm{m} ; h_{f-p}$ - average depth of the floodplain (greater and lesser), g.

Determine the Froude number:

$F r=\frac{Q_{r i v}^{2} B_{r i v}}{g \omega_{r i v}^{3}}$.

Determine the value of full backwater:

$$
\xi=1-0.5 \operatorname{Fr} \frac{\beta_{b r}^{2}-1}{\left(\frac{\beta_{b r}^{2}}{2 \beta_{b r}-1}\right)^{0,3}-1} .
$$


Determine the length of the compression zone:

$l_{z_{-} c}=\xi \cdot l_{z_{-} b r}$.

Determine the length of the spreading zone:

$$
l_{z_{-} s}=(1-\xi) l_{z_{-} c} .
$$

The parameters of the central jet in the spreading zone are determined:

$$
R_{z_{-} s}=\frac{l_{z_{-} s} \beta_{b r}}{\beta_{b r}-1} .
$$

The parameters of the central jet in the compression zone are determined:

$$
R_{z_{-} c}=\frac{l_{z_{-} c} \beta_{b r}}{\beta_{b r}-1} .
$$

The step of the longitudinal coordinate of the calculated alignment is assigned, the total length of the section is determined as:

$$
l_{i}=\sum_{i=0}^{i} \Delta l_{i}=l_{i-1}+\Delta l_{i},
$$

where $l_{i}$ varies from 0 to $l_{z_{-} c}$ in the compression zone and from 0 to $l_{z_{-} s}$ in the spreading zone.

Calculate the values of the curve of the free surface of the river flow in the influence zone of the bridge crossing. Determination of the influence zone of the bridge crossing is based on the equation of stable uneven movement in open channels in a one-dimensional formulation. The proposed approach to solving the problem is based on the solution, according to [11], by the method of Yu. Abramov using the properties of the central stream of the river flow in the zone of artificial compression. The finite-difference analogue of the differential equation, which describes the change in flow depths, has the form:

$$
\begin{aligned}
& h_{i}-h_{i-1}=J\left(l_{i}-l_{i-1}\right)-J R\left[\left(1-\frac{l_{i}}{R}\right)^{-1}-\left(1-\frac{l_{i-1}}{R}\right)^{-1}\right] \pm \\
& \pm \frac{J h_{r}^{4 / 3} m^{2}}{2 g}\left[\left(1-\frac{l_{i}}{R}\right)^{-2}-\left(1-\frac{l_{i-1}}{R}\right)^{-2}\right],
\end{aligned}
$$

where $m$ - the reciprocal of the channel roughness coefficient $n, m=1 / n ; R$ - parameter of the central jet; $l_{i}-$ longitudinal coordinate of the calculated section, $\mathrm{m} ; \mathrm{g}-$ acceleration of gravity, $\mathrm{m} / \mathrm{s}^{2}$.

Initial conditions: $h=h_{0}$ at $l=0 ; h=h_{i}$ at $l=l_{i}$. All calculations are made, respectively, for each branch of a flood for a certain day. Calculations should start with the full spreading alignment, where all hydraulic characteristics of the flow have natural values, the third term in equation (12) is taken with the «+» sign. Moreover $l_{i-1}=0$, but $l_{i}$ changes in the spreading zone from 0 to $l_{z_{-} s}$. The value of the parameter of the central jet in the spreading zone is $R=R_{z} s$. The value $l_{i}=l_{z s}$ corresponds to the value of the bridge backwater.

Having reached the bridge alignment, to continue the calculation in the compression zone, it is necessary to replace the sign in front of the third term with «-». Give the value $h_{i-1}$ to the value of the obtained depth under the bridge, accept the distance $l_{i-1}=0$ and change the value of the central jet parameter in the compression zone $R=R_{z_{-}}$. The value $l_{i}$ ranges from 0 to $l_{z_{c} c}$ value that is the distance from the bridge to the beginning of the compression zone where a full backwater is formed under the bridge.

Based on equation (12), the slope of the free surface of the river flow is calculated:

$$
\begin{aligned}
& I_{x_{1}}=\frac{h_{i}-h_{i-1}}{l_{i}-l_{i-1}}=J-\frac{J R}{l_{i}-l_{i-1}}\left[\left(1-\frac{l_{i}}{R}\right)^{-1}-\left(1-\frac{l_{i-1}}{R}\right)^{-1}\right] \pm \\
& \pm \frac{J h_{r}^{4 / 3} n^{-2}}{2 g\left(l_{i}-l_{i-1}\right)}\left[\left(1-\frac{l_{i}}{R}\right)^{-2}-\left(1-\frac{l_{i-1}}{R}\right)^{-2}\right] .
\end{aligned}
$$

Changing the slope of the free surface will make it possible to clarify the boundaries of the compression and spreading zones in the alignment of the bridge crossing.

\section{Research results}

The calculation of the influence zone of the bridge was carried out on the river. Seversky Donets near the village. Brusovka on the T-05-14 highway, km 83+575, Donetsk region (Ukraine). Every year, during the spring flood and rainfall floods, the floodplain is flooded to a depth of 0.5 to $3.3 \mathrm{~m}$ for $1-2$ weeks, on depressions the water stays for 1-3 months. The initial calculation data are given in Table 1.

The output parameters of the computational domain are presented in the graphs (Fig. 1).
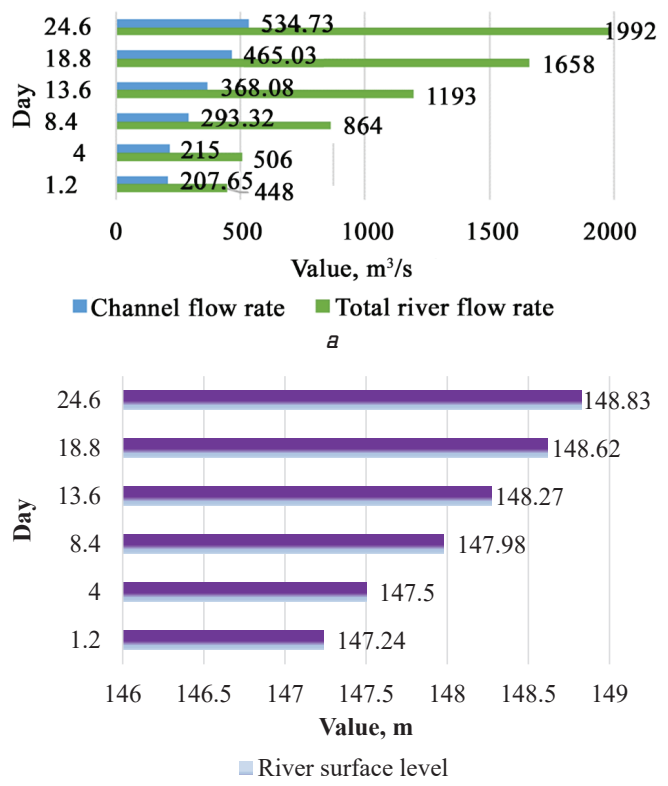

b

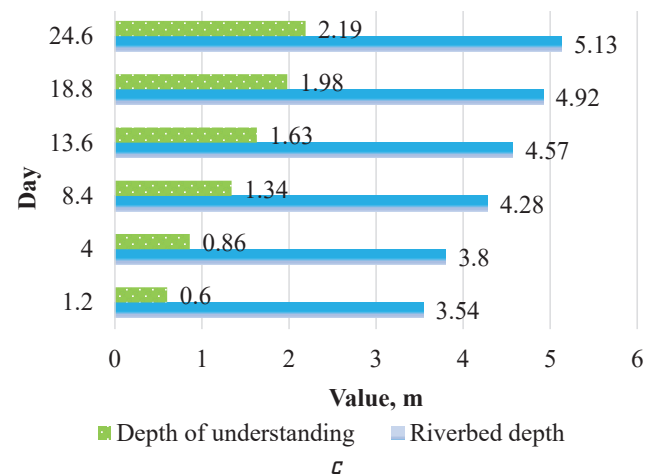

Fig. 1. Initial parameters of the computational domain of Seversky Donets: $a$ - total $\emptyset_{r i v}$ and channel $\emptyset_{r}$ flow rates of the river; $b$ - level of the river surface, $\mathrm{H} ; c$ - distribution of channel $h_{\Gamma}$ and floodplain $h_{f-p}$ depths 
The calculation results for the influence zone of the bridge crossing are shown in Fig. 2, 3. In Fig. 2 shows the calculation of the specific discharge of floodplains according to the relation (1), where for each next stage of flooding there is an increase in discharge for more than 24 days. According to formulas (3), (7), (9), the values of compression and spreading zones of the river flow in the general influence zone of the bridge crossing are obtained. Here, with increasing flow rates, a general increase in the length of the influence zone is observed, as well as an increase in the compression zone, an increase and then a decrease, after the 8th day, of the spreading zone. Accordingly, a change in the parameters of the central jet is observed in the compression and spreading zones obtained with relations (9), (10), Fig. 2, b, c.

After calculating the values of the zone of compression and spreading, the distribution of river flow depths was obtained (Fig. 3, a), where it is possible to determine the change in depths directly in the section of the bridge crossing.
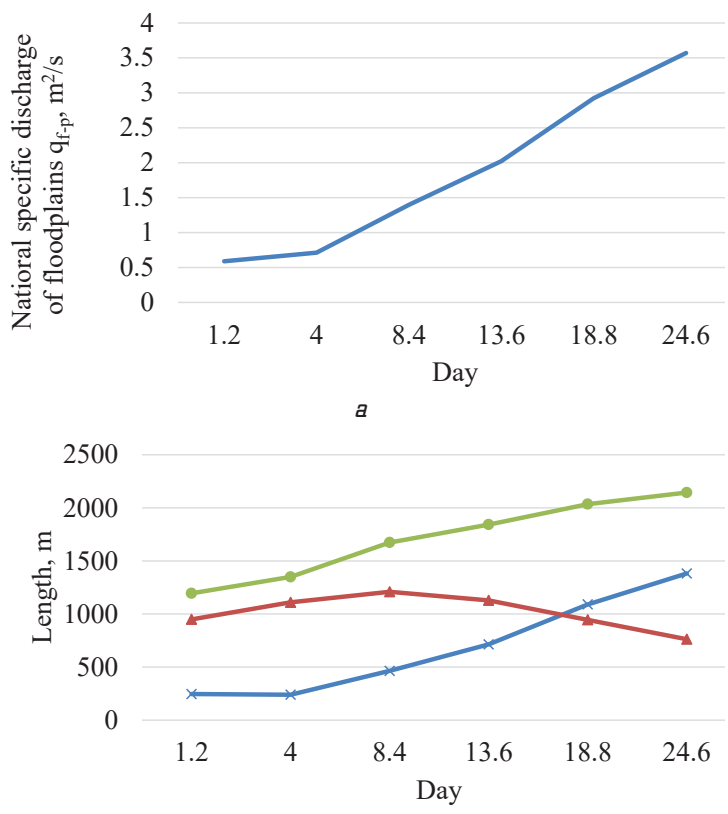

*Compression zone length $1 z \_c$

$\rightarrow$ Spreading zone length $1 z \_s$

$\rightarrow$ Length of the influence of the bridge crossing $1 z_{-} b r$

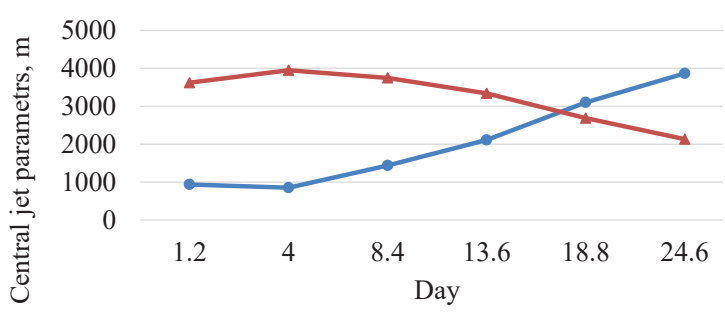

$\rightarrow$ Central jet parameters in the compression zone Rz_c

$\rightarrow$ Central jet parameters in the spreading zone $\mathrm{Rz}_{-} \mathrm{S}$

c

Fig. 2. The calculated parameters of the computational domain of the Seversky Donets: $a$ - natural specific discharge of floodplains; $b$ - length of the influence zone of the bridge crossing, the length of the zones of compression and spreading; $c$ - parameters of the central jet in the compression and spreading zones

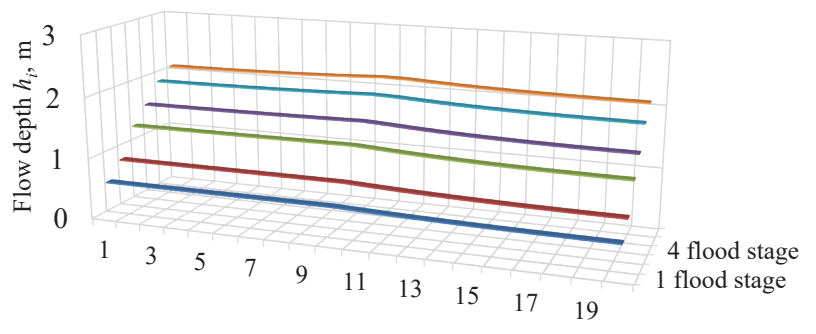

Calculation steps for the length of the river section

$\square 1$ flood stage $\square 2$ flood stage $\square 3$ flood stage

घ 4 flood stage $\square 5$ flood stage $\square 6$ flood stage

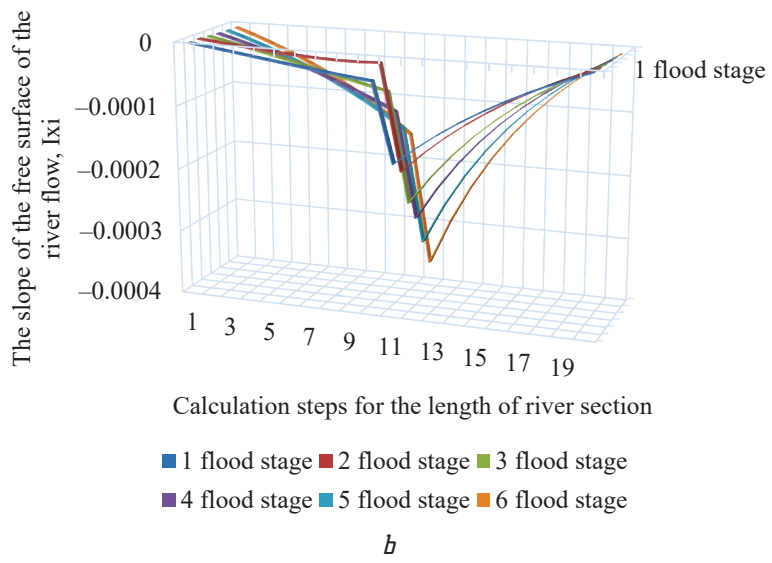

Fig. 3. The calculated parameters of the computational domain of Seversky Donets on each flood branch for a certain day: a - slope of the free surface of the river flow; $b$ - flow depth

The boundaries of the compression and spreading zones can be more clearly determined by the change in the slope of the water surface, determined by equation (13). In the presented graph (Fig. $3, b$ ), at the 10th step of the calculation, a change in the inclined free surface in the alignment of the bridge crossing is observed. The fall is inclined - from 10 to 12 steps, the rise - at 12 steps of all stages of the flood.

\section{SWOT analysis of research results}

Strengths. The proposed method, based on the change in the flood width and the depth of the river flow, makes it possible to determine the parameters of the influence zone of the bridge crossing, within which limits to calculate the general and local deformations in the channel and on the floodplain during floods.

Weaknesses. A rather laborious process of calculation, it requires a large amount of initial data, which is necessary and difficult to obtain in full-scale conditions.

Opportunities. The studies carried out are the initial conditions for predicting deformations or eroded processes, both in the channel and in the floodplain areas of lowland rivers.

Threats. Depends on the accuracy and reliability of the initial data, which can be obtained during long-term field observations by specialists of appropriate qualifications.

\section{Conclusions}

1. Based on the consideration of hydraulic phenomena at the bridge crossing, a method for determining the pa- 
rameters of the zone of its influence has been developed. The proposed method makes it possible to obtain the lengths of the compression and spreading zones, changes in the depth and slope of the free surface of the river flow. Numerical studies must be carried out, respectively, on each branch of a flood or flood, on a certain day, and begin with a full spreading alignment, where all hydraulic characteristics of the flow have natural values.

2. The influence zone of the bridge crossing on the river was determined. Seversky Donets, where the development of general channel deformations and erosion takes place in the channel and on the floodplains, which varies from $1195 \mathrm{~m}$ to $2144 \mathrm{~m}$. the spreading zone, which, in the course of the flood, accordingly decreases from $949 \mathrm{~m}$ to $762 \mathrm{~m}$. The parameters of the central jet vary in accordance with the distribution of the compression and spreading zones. Based on the equation of stable irregular movement in open channels, a change in the flow depth was obtained, which increases from $0.58 \mathrm{~m}$ to $2.17 \mathrm{~m}$ in the section of the bridge crossing. changes on the first line of the flood from -0.00016 to -0.00018 , on the sixth - from -0.00032 to -0.00037 . The results are the basis for conducting research on predicting the development of deformation processes in a river flow, taking into account artificial compression, in the influence zone of the bridge crossing.

\section{References}

1. Bridge, J. S. (1993). The interaction between channel geometry, water flow, sediment transport and deposition in braided rivers. Geological Society, London, Special Publications, 75 (1), 13-71. doi: http://doi.org/10.1144/gsl.sp.1993.075.01.02

2. Grenfell, S. E., Ellery, W. N., Grenfell, M. C. (2009). Geomorphology and dynamics of the Mfolozi River floodplain, KwaZulu-Natal, South Africa. Geomorphology, 107 (3-4), 226-240. doi: http://doi.org/10.1016/j.geomorph.2008.12.011

3. Larsen, E. W. Greco, S. E. (2002). Modeling Channel Management Impacts on River Migration: A Case Study of Woodson Bridge State Recreation Area, Sacramento River, California, USA. Environmental Management, 30 (2), 209-224. doi: http:// doi.org/10.1007/s00267-002-2663-1
4. Larsen, R. J., Ting, F. C. K., Jones, A. L. (2011). Flow Velocity and Pier Scour Prediction in a Compound Channel: Big Sioux River Bridge at Flandreau, South Dakota. Journal of Hydraulic Engineering, 137 (5), 595-605. doi: http://doi.org/10.1061/ (asce)hy.1943-7900.0000334

5. Okamoto, T., Takebayashi, H., Sanjou, M., Suzuki, R., Toda, K. (2019). Log jam formation at bridges and the effect on floodplain flow: A flume experiment. Journal of Flood Risk Management, 13 (S1). doi: http://doi.org/10.1111/jfr3.12562

6. Cardoso, A. H., Bettess, R. (1999). Effects of Time and Channel Geometry on Scour at Bridge Abutments. Journal of Hydraulic Engineering, 125 (4), 388-399. doi: http://doi.org/10.1061/ (asce)0733-9429(1999)125:4(388)

7. Gautam, M. R., Watanabe, K., Ohno, H. (2004). Effect of bridge construction on floodplain hydrology-assessment by using monitored data and artificial neural network models. Journal of Hydrology, 292 (1-4), 182-197. doi: http://doi.org/10.1016/ j.jhydrol.2003.12.026

8. Fewtrell, T. J., Neal, J. C., Bates, P. D., Harrison, P. J. (2011) Geometric and structural river channel complexity and the prediction of urban inundation. Hydrological Processes, 25 (20), 3173-3186. doi: http://doi.org/10.1002/hyp.8035

9. Arefev, N. V., Mikhalev, M. A., Skvortsova, O. S. (2008). Obschii razmyv rusla i ponizhenie urovnia vody $\mathrm{v}$ nizhnem befe vodokhranilischnykh gidrouzlov. Prirodoobustroistvo, 1, 83-87. Available at: http://www.eecca-water.net/file/Arefev-N.V.-Obschiy-razmyv-rusla.pdf

10. Neilands, R., Gjunsburgs, B., Neilands, R. R. Theoretical analysis of the method of scour development in time during the flood. Available at: https://ortus.rtu.lv/science/lv/publications/4859/fulltext

11. Slavinska, O. S., Kozarchuk, I. A. (2011). Doslidzhennia protsesu zahalnoho rozmyvu v zonakh vplyvu mostovykh perekhodiv z hrupovymy otvoramy. Avtomobilni dorohy i dorozhnie budivnytstoo, 82, 164-172. Available at: http://publications.ntu.edu.ua/ avtodorogi i stroitelstvo/82/164-172.pdf

12. Tkachuk, S. H. (2004). Prohnozuvannia ruslovykh deformatsii na mostovykh perekhodakh. Chastyny $3 i$. Kyiv: NTU, 98.

Slavinska Olena, Doctor of Technical Sciences, Professor, Dean of the Faculty of Transport Construction, National Transport University, Kyiv, Ukraine, ORCID: http://orcid.org/0000-0002-9709-0078, e-mail: elenaslavin9@gmail.com

Tsynka Anatolii, First Deputy Director, M. P. Shulgin State Road Research Institute State Enterprise, Kyiv, Ukraine, ORCID: http:// orcid.org/0000-0002-0357-2325, e-mail: anatoliy.tsynka@gmail.com 